\title{
Health Services Utilization Among Fee-for-Service Medicare and Medicaid Patients Under Age 65 with Behavioral Health IIIness at an Urban Safety Net Hospital
}

\author{
Ramon S. Cancino, MD, MSc; Brian W. Jack, MD; John Jarvis, BA; Alice Kate Cummings, BA; \\ Ellie Cooper, BA; Pierre-Yves Cremieux, PhD; and James F. Burgess, Jr., PhD
}

\begin{abstract}
BACKGROUND: In 2011, fee-for-service patients with both Medicare and

Medicaid (dual eligible) sustained $\$ 319.5$ billion in health care costs.

OBJECTIVE: To describe the emergency department (ED) use and hospital admissions of adult dual eligible patients aged under 65 years who used an urban safety net hospital.

METHODS: This was a retrospective database analysis of patients aged between 18 and 65 years with Medicare and Medicaid, who used an urban safety net academic health center between January 1, 2011, and December 31, 2011. We compared patients with and without behavioral health illness. The main outcome measures were hospital admission and ED use. Chi-square and Wilcoxon rank-sum tests were used for descriptive statistics on categorical and continuous variables, respectively. Greedy propensity score matching was used to control for confounding factors. Rate ratios (RR) and 95\% confidence intervals (Cl) were determined after matching and after adjusting for those variables that remained significantly different after matching.
\end{abstract}

RESULTS: In 2011, 10\% of all fee-for-service dual eligible patients aged less than 65 years in Massachusetts were seen at Boston Medical Center. Data before propensity score matching showed significant differences in age, sex, race/ethnicity, marital status, education, employment, physical comorbidities, and Charlson Comorbidity Index score between patients with and without behavioral health illness. Analysis after propensity score matching found significant differences in sex, Hispanic race, and other education and employment status. Compared with patients without behavioral health illness, patients with behavioral health illness had a higher RR for hospital admissions ( $\mathrm{RR}=2.07 ; 95 \% \mathrm{Cl}=1.81-2.38 ; P<0.001)$ and $\mathrm{ED}$ use $(\mathrm{RR}=1.61 ; 95 \% \mathrm{Cl}=1.46-1.77 ; P<0.001)$. Results were robust after adjusting for characteristics that remained statistically significantly different after propensity score matching.

CONCLUSIONS: Adult dual eligible patients aged less than 65 years with behavioral health illness in the Medicaid fee-for-service plan had significantly higher rates of hospital admission and ED use compared with dual eligible patients without behavioral health illness at the largest urban safety net medical center in New England. Safety net hospitals care for a large proportion of dual eligible patients with behavioral health illness. Further research is needed to elucidate the systems-related and patient-centered factors contributing to the utilization behaviors of this patient population.

J Manag Care Spec Pharm. 2017;23(7):781-88

Copyright $\odot 2017$, Academy of Managed Care Pharmacy. All rights reserved.

\section{What is already known about this subject}

Fee-for-service patients with Medicare and Medicaid are among the sickest, poorest, and most costly in the United States. One third of dual eligible patients are aged under 65 years and account for $37 \%$ of all dual eligible spending.

\section{What this study adds}

In a safety net hospital dual eligible patient population, there are significantly higher rates of hospital admissions and emergency department use for those with behavioral health illness compared with those without behavioral health illness.

In Massachusetts, 11\% of dual eligible patients aged under 65 years used the largest safety net hospital in New England.

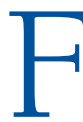
ee-for-service patients with both Medicare and Medicaid (dual eligible) are among the sickest, poorest, and most costly in the United States. ${ }^{1}$ In 2011, 9 million dual eligible beneficiaries nationwide incurred health care costs estimated at $\$ 319.5$ billion. $^{2}$ Dual eligible patients account for one third of all Medicare hospital stays, even though they represent approximately $18 \%$ of beneficiaries. Compared with other Medicare beneficiaries, dual eligible patients are more than twice as likely to be hospitalized for asthma, diabetes, and pressure ulcers. They are 52\% more likely to be hospitalized for urinary tract infections, and 30\% more likely to be hospitalized for chronic obstructive pulmonary disease and bacterial pneumonia. ${ }^{3}$ In general, dual eligibility is positively correlated with the likelihood of inpatient hospital utilization. ${ }^{4}$ Dual eligible patients, then, are an important group for study and intervention to improve health outcomes and address health care utilization.

One third of dual eligible patients are aged under 65 years, and this group accounts for $37 \%$ of all dual eligible beneficiary spending. ${ }^{5}$ These "young duals" have mental or physical disabilities that qualify them for Medicare benefits, and nearly half live with severe and persistent mental illness. ${ }^{6}$ Compared with $48 \%$ of dual eligible patients aged 65 years and older, nearly $78 \%$ of young duals lived with cognitive or mental impairment in 2008. ${ }^{5}$ Approximately $28 \%$ of young duals have depression, 
and $12 \%$ are estimated to have schizophrenia or bipolar disorder. Young dual eligible patients have accounted for half of the total dual eligible hospital stays for asthma and diabetes. ${ }^{3}$ Young dual eligible patients are more likely to encounter problems with accessing dental care, medical care, and prescription medications than older dual eligible patients. ${ }^{6}$ This dual eligible group is important because a large number have mental illness compounded by issues of health care access, low educational attainment, low socioeconomic status, and difficulty navigating a complex health care system. ${ }^{7}$

Expenditures for dual eligible patients with behavioral health illness exceeds $\$ 3.2$ billion per year. ${ }^{5}$ There is a lack of evidence regarding the utilization pattern of those dual eligible beneficiaries aged under 65 years with behavioral health illness. A better understanding of this population's health care utilization can allow for better planning and education around pharmacy benefits and risk. ${ }^{7,8}$

The purpose of this study was to describe emergency department (ED) use and hospital admissions of adult dual eligible patients aged under 65 years who used Boston Medical Center, an urban safety net hospital.

\section{Methods}

A retrospective cross-sectional analysis of hospital system administrative data was conducted from January 1, 2011, through December 31, 2011. The setting was Boston Medical Center, an urban safety net medical center in Boston, Massachusetts, and the largest such hospital in New England.

\section{Inclusion and Exclusion Criteria}

The study population consisted of patients aged 18 through 65 years with both Medicare and Medicaid health insurance coverage with at least 1 ambulatory, ED, or hospital admission in 2011 (study period). Patient demographic information was recorded as of the first observed visit on or after January 1, 2011.

Patients with incomplete demographic information were excluded. Patients were also excluded if their records indicated that they were enrolled in a managed care organization as defined by Boston Medical Center.

\section{Independent and Dependent Variables}

The primary independent variable was the diagnosis of any behavioral health illness, defined as disorders characterized by dysregulation of mood, thought, and/or behavior as recognized by the American Psychiatric Association's Diagnostic and Statistical Manual, 4th edition. ${ }^{9}$ Behavioral health illness was identified in the hospital system administrative data by the presence of hospital visits with at least 1 diagnosis code, as defined by the International Classification of Diseases, Ninth Revision, Clinical Modification (ICD-9-CM) codes (Appendix, available in online article). ${ }^{10}$

The primary dependent variables were ED encounters and hospital admissions at Boston Medical Center within the study period. ED encounters that resulted in a hospital admission were considered related to the subsequent hospitalization. Hospital admissions were defined as encounters that resulted in a hospital stay.

\section{Control Variables}

Patient-level covariates were controlled for based on the theoretical framework described by Andersen's Behavioral Model. ${ }^{11}$ Andersen described patient health care utilization patterns as a culmination of predisposing characteristics, enabling resources (at the patient and community level) and need (perceived and actual). This study focused on those measurable covariates related to predisposing characteristics and need.

Predisposing factors included age, sex, race, and marital status. Need was characterized by Charlson Comorbidity Index (CCI) scores as defined in Quan et al. (2005). ${ }^{12,13}$ ICD-9-CM codes drawn from hospital system administrative data were used to identify existing physical comorbidities..$^{10,13}$

\section{Statistical Analysis}

Patient age and CCI score were treated as continuous variables. Gender was treated as a dichotomous variable. Race/ethnicity, marital status, level of educational attainment, and employment status were treated as categorical variables.

Descriptive and bivariate statistics assessed differences in patient characteristics between dual eligible patients with and without behavioral health illness. Chi-square tests were used to compare differences between cohorts for dichotomous and categorical variables. Wilcoxon nonparametric rank-sum tests were used to compare unadjusted differences for continuous variables.

The mean numbers of ED use and hospital admissions per year were calculated using the numbers of events per patient per year. The unit of analysis for utilization comparisons was the patient. Incidence of utilization was calculated using the number of utilization events divided by patients.

To replicate some of the benefits of a randomized controlled trial in this observational study, a propensity score-matched analysis was conducted. A logistic model was developed to predict patient propensities for behavioral health illness with age, gender, race, marital status, educational attainment, employment status, physical comorbidities, and CCI score as independent variables. Propensity score matching was conducted without replacement using greedy one-to-one match methods. A modified nearest-neighbor approach was employed with a caliper distance of one half the standard deviation in patients' predicted propensity score. A sensitivity analysis was conducted using a caliper distance of one quarter the standard deviation in patients' predicted propensity score.

Rate ratios (RRs) and confidence intervals (CIs) after propensity score matching were estimated using generalized linear model (GLM) regressions with a log link function to transform the expectation of the response variable into a linear 


\section{Health Services Utilization Among Fee-for-Service Medicare and Medicaid Patients Under Age 65 with Behavioral Health IIIness at an Urban Safety Net Hospital}

\section{TABLE 1 Demographics and Comorbidities of Adult Dual Eligible Patients Under Age 65}

Stratified by Presence of Behavioral Health IIIness, 2011

\begin{tabular}{|c|c|c|c|c|c|}
\hline & \multicolumn{2}{|c|}{$\begin{array}{c}\text { Patients with } \\
\text { Behavioral Health Illness } \\
(\mathrm{n}=3,174)\end{array}$} & \multicolumn{2}{|c|}{$\begin{array}{c}\text { Patients Without } \\
\text { Behavioral Health Illness } \\
(\mathbf{n}=7,470)\end{array}$} & $P$ Value \\
\hline \multicolumn{6}{|l|}{ Demographics $^{b}$} \\
\hline Age on January 1, 2011, mean (SD) & 46.4 & $(11.1)$ & 46.3 & $(12.8)$ & $0.044 c$ \\
\hline Female, n (\%) & 1,507 & $(47.5)$ & 4,061 & $(54.4)$ & $<0.001^{\mathrm{c}}$ \\
\hline \multicolumn{6}{|l|}{ Race/ethnicity, n (\%) } \\
\hline White & 1,254 & $(39.5)$ & 2,354 & $(31.5)$ & $<0.001^{\mathrm{c}}$ \\
\hline Non-Hispanic black & 1,304 & $(41.1)$ & 2,812 & $(37.6)$ & $<0.001^{c}$ \\
\hline Hispanic & 491 & $(15.5)$ & 1,687 & $(22.6)$ & $<0.001^{\mathrm{c}}$ \\
\hline Other/unknown & 125 & $(3.9)$ & 617 & $(8.3)$ & $<0.001^{c}$ \\
\hline \multicolumn{6}{|l|}{ Marital status, $\mathrm{n}(\%)$} \\
\hline Single & 2,258 & $(71.1)$ & 4,927 & $(66.0)$ & $<0.001^{\mathrm{c}}$ \\
\hline Married & 339 & $(10.7)$ & 1,235 & $(16.5)$ & $<0.001^{\mathrm{c}}$ \\
\hline Divorced/separated & 453 & (14.3) & 904 & $(12.1)$ & $0.002 \mathrm{c}$ \\
\hline Other/unknown & 124 & (3.9) & 404 & $(5.4)$ & $0.001^{\mathrm{c}}$ \\
\hline \multicolumn{6}{|l|}{ Education, $\mathrm{n}(\%)$} \\
\hline$\leq$ High school & 2,193 & $(69.1)$ & 4,620 & $(61.8)$ & $<0.001^{\mathrm{c}}$ \\
\hline Some college & 256 & $(8.1)$ & 582 & $(7.8)$ & 0.631 \\
\hline College graduate & 401 & $(12.6)$ & 896 & $(12.0)$ & 0.356 \\
\hline None & 79 & $(2.5)$ & 310 & $(4.1)$ & $<0.001^{\mathrm{c}}$ \\
\hline Other/unknown & 245 & $(7.7)$ & 1,062 & $(14.2)$ & $<0.001^{\mathrm{c}}$ \\
\hline \multicolumn{6}{|l|}{ Employment status, n (\%) } \\
\hline Full time & 69 & $(2.2)$ & 235 & $(3.1)$ & $0.006^{c}$ \\
\hline Part time & 71 & $(2.2)$ & 249 & $(3.3)$ & $0.002^{c}$ \\
\hline Disabled & 1,479 & $(46.6)$ & 2,789 & $(37.3)$ & $<0.001^{\mathrm{c}}$ \\
\hline Unemployed & 1,308 & $(41.2)$ & 3,125 & $(41.8)$ & 0.550 \\
\hline Other/unknown & 247 & $(7.8)$ & 1,072 & $(14.4)$ & $<0.001^{\mathrm{c}}$ \\
\hline \multicolumn{6}{|l|}{ Physical comorbidities, n (\%) } \\
\hline Chronic pulmonary disease & 600 & $(18.9)$ & 651 & $(8.7)$ & $<0.001^{\mathrm{c}}$ \\
\hline Diabetes without chronic complications & 392 & $(12.4)$ & 661 & $(8.8)$ & $<0.001^{\mathrm{c}}$ \\
\hline Moderate or severe liver disease & 327 & $(10.3)$ & 339 & $(4.5)$ & $<0.001^{\mathrm{c}}$ \\
\hline Diabetes with chronic complications & 206 & $(6.5)$ & 483 & $(6.5)$ & 0.963 \\
\hline Renal disease & 194 & $(6.1)$ & 339 & $(4.5)$ & $<0.001^{\mathrm{c}}$ \\
\hline AIDS/HIV & 205 & $(6.5)$ & 204 & $(2.7)$ & $<0.001^{\mathrm{c}}$ \\
\hline Congestive heart failure & 141 & $(4.4)$ & 236 & $(3.2)$ & $0.001^{\mathrm{c}}$ \\
\hline Peripheral vascular disease & 120 & $(3.8)$ & 191 & $(2.6)$ & $<0.001^{\mathrm{c}}$ \\
\hline Cancer & 103 & $(3.2)$ & 243 & $(3.3)$ & 0.983 \\
\hline Cerebrovascular disease & 97 & (3.1) & 184 & $(2.5)$ & 0.081 \\
\hline Myocardial infarction & 99 & $(3.1)$ & 128 & $(1.7)$ & $<0.001^{\mathrm{c}}$ \\
\hline Hemiplegia or paraplegia & 60 & $(1.9)$ & 172 & $(2.3)$ & 0.183 \\
\hline Rheumatic disease & 38 & $(1.2)$ & 142 & $(1.9)$ & $0.010^{c}$ \\
\hline Metastatic solid tumor & 32 & $(1.0)$ & 64 & $(0.9)$ & 0.450 \\
\hline Peptic ulcer disorder & 17 & $(0.5)$ & 32 & $(0.4)$ & 0.455 \\
\hline Dementia & 16 & $(0.5)$ & 4 & $(0.1)$ & $<0.001^{\mathrm{c}}$ \\
\hline Charlson Comorbidity Index, mean (SD) & 1.4 & $(2.3)$ & 0.9 & $(1.7)$ & $<0.001^{\mathrm{c}}$ \\
\hline
\end{tabular}

apatients were defined as having a behavioral health illness if they had a medical visit to the Boston Medical Center from January 1, 2011, to December 31, 2011, with a corresponding diagnosis for any behavioral health illness.

bPatient demographic information recorded as of January 1, 2011 (or first available visit after January 1, 2011).

cP values $<0.05$; calculated using chi-square tests for categorical variables and Wilcoxon rank-sum tests for continuous variables.

AIDS/HIV = acquired immunodeficiency syndrome/human immunodeficiency virus; $S D=$ standard deviation 


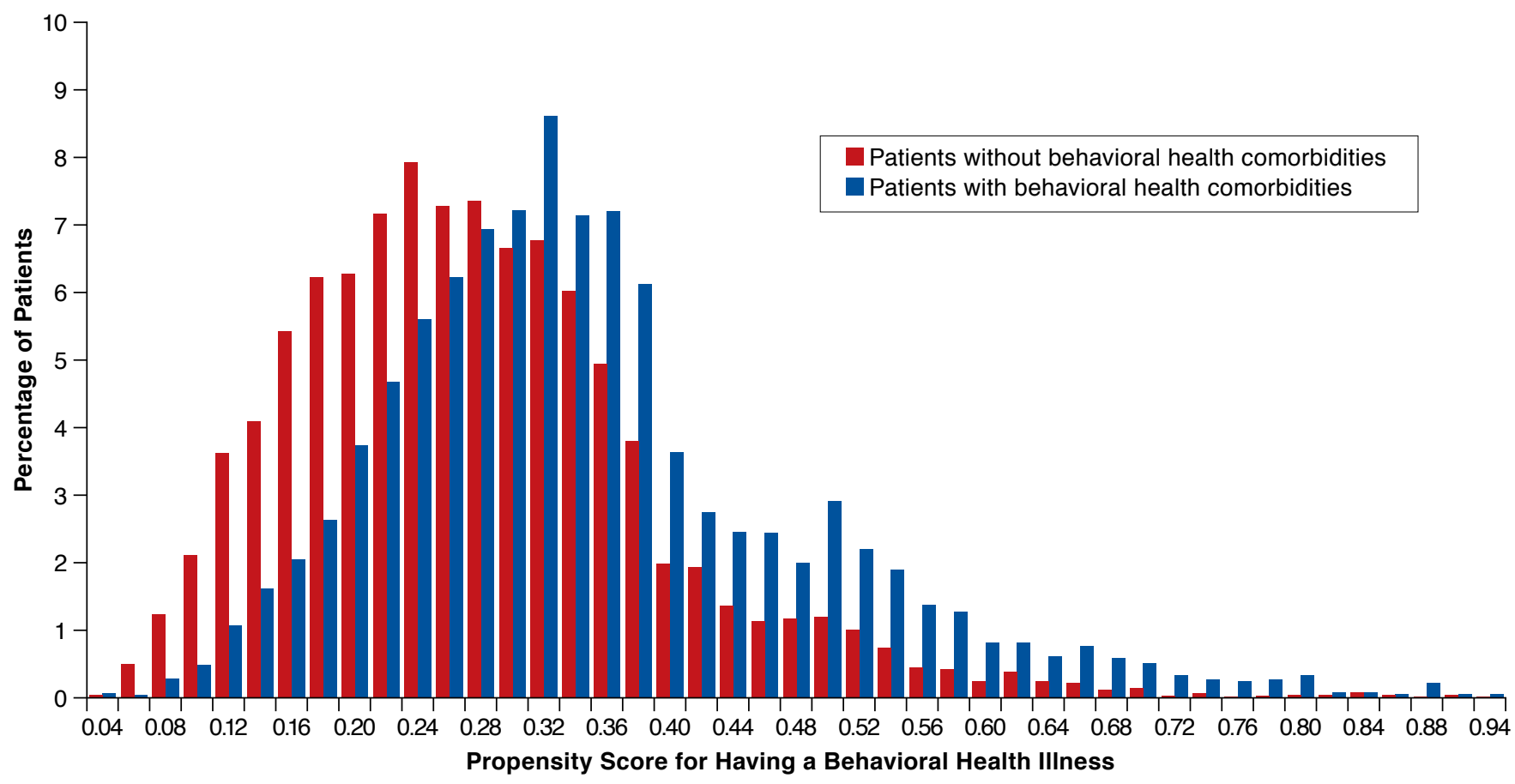

Notes: The propensity score for having a behavioral health comorbidity is the probability given demographic characteristics and physical comorbidities that a patient was diagnosed with a behavioral health comorbidity in 2011. A patient's propensity for having a behavioral health comorbidity was derived using a logistic regression that controlled for gender, race, marital status, education level, employment status, and physical comorbidities. All analyses were conducted among dual eligible patients at Boston Medical Center.

predictor. GLM models were used to account for non-normal distribution in the dependent variables (ED encounters and hospital admissions). The equal variance assumption was not met; therefore, a negative binomial distribution was chosen over a Poisson distribution. An analysis was conducted using a single covariate flag for behavioral health illness, with repeated subject measures to account for patient matching. CIs were calculated considering 2 independent samples with a dichotomous outcome variable. The estimated parameter was the ratio of utilization between dual eligible patients with and without behavioral health illness.

After matching, regression-adjusted RRs were calculated using GLM regressions with a log link function and negative binomial distribution. Adjusted GLM models included covariates, which remained statistically significant after matching $(P<0.05)$.

Sensitivity analyses were conducted for 2 previous years (2009 and 2010) to assess for trends in data. Sensitivity analyses were also conducted for those patients enrolled in a managed care organization as defined by Boston Medical Center in order to assess for differences in this population compared with those not enrolled in managed care organizations.
Data analysis was generated using SAS software version 8 (SAS Institute, Cary, NC). Human subject approval for these analyses was obtained from the Institutional Review Board at Boston University School of Medicine.

\section{Results}

\section{Before Propensity Score Matching}

A total of 12,845 unique dual eligible patients aged less than 65 years were identified who used Boston Medical Center in 2011. Among these patients, 3 were excluded because of incomplete demographic data, and 1,098 patients were excluded because their health insurance coverage was provided by a managed care organization, which left 10,644 unique fee-for-service dual eligible patients for the final study.

A total of 3,174 patients were identified with behavioral health illness, and 7,470 were identified without behavioral health illness (Table 1). A smaller proportion of patients with behavioral health illness were female, compared with those without behavioral health illness (47.5\% vs 54.4\%; $P<0.001$ ). Among patients with behavioral health illness, a larger proportion were white or non-Hispanic black, single, divorced, 
or separated; had less than a high school education; and were disabled, while fewer were employed full time or part time.

Among the 16 physical comorbidities reported in Table 1 , higher propensity of disease was reported among patient with behavioral health illness except for diabetes with chronic complications, cancer, cerebrovascular disease, hemiplegia or paraplegia, metastatic solid tumor, and peptic ulcer disorder. As a result, patients with behavioral health illness had a significantly higher burden of overall comorbidity based on the CCI score (1.4 vs. $0.9 ; P<0.001)$.

\section{After Propensity Score Matching}

Following propensity score matching, 3,089 patients were included in each patient cohort. The distributions shown in Figure 1 illustrate considerable overlap and similarly shaped distributions of propensity scores between both groups, which ensured good availability of appropriate matches.

Demographic characteristics after propensity score matching were similar between dual eligible patients aged under 65 years with and without behavioral health illness (Table 2). After matching, sex, Hispanic ethnicity, other/unknown education, and other/unknown employment status were the only patient characteristics that remained statistically significant. Physical comorbidities were also similar after matching between dual eligible patients aged under 65 years with and without behavioral health illness. CCI scores between both cohorts were similar after matching, and there were no statistically significant differences in rates of physical comorbidities comprising the CCI calculation.

After propensity score matching, health care resource utilization in 2011 was compared between sample patients with and without behavioral health illness (Table 3). Descriptive counts and rates were compared between patient cohorts for hospitalizations and ED visits, as well adjusted RRs and 95\% CIs for both measures of resource utilization.

Study sample patients with behavioral health illness experienced 1,398 hospital admissions in 2011 (0.45 admissions per patient). Sample patients without behavioral health illness experienced 675 hospital admissions in 2011 (0.22 admissions per patient). The corresponding postmatch RR for hospitalizations between cohorts in 2011 was 2.07 (95\% CI=1.81-2.38; $P<0.001)$. After adjusting for patient characteristics, which remained statistically significant after propensity score matching (gender, Hispanic race, other or unknown employment, and education), the RR was 2.14 (95\% CI = 1.87-2.46; $P<0.001$ ).

Study sample patients with behavioral health illness experienced 3,354 ED visits in 2011 (1.09 visits per patient). Sample patients without behavioral health illness experienced 2,089 ED visits in 2011 (0.68 visits per patient). The corresponding RR after propensity score matching for ED visits between cohorts in 2011 was 1.61 (95\% CI=1.46-1.77; $P<0.001)$. After adjusting for patient characteristics, which remained statistically significant after propensity score matching (gender, Hispanic race, other or unknown employment, and education), the RR was 1.64 (95\% CI=1.49-1.81; $P<0.001)$.

\section{Discussion}

This study of fee-for-service dual eligible patients aged under 65 years seen at a safety net hospital demonstrated significantly higher rates of hospital admissions and ED use by those patients with behavioral health illness as compared with those without behavioral health illness. Previous research has found that dual eligibility is also correlated with the likelihood for home health services use and hospital readmission. ${ }^{4,14}$ Previous research in this area has demonstrated that, since the expansion of Medicare Part D, dual eligible patients with behavioral health illness continue to be at risk for poor medication access. ${ }^{15,16}$ Poor access to medication compounded by the social challenges of this population could explain our findings. Our findings add to the literature studying the outcomes of a subpopulation of dual eligible patients at an urban safety net hospital.

This study's results indicate that 12,845 dual eligible patients aged under 65 years used Boston Medical Center in 2011. This number indicates that $11 \%$ of the 115,000 dual eligible patients aged under 65 years in Massachusetts used the same safety net hospital at least once. To our knowledge, this is the first data to show the burden of utilization that safety net hospital undertake for dual eligible patients aged under 65 years. In 2009, estimates show that dual eligible patients represented 24\% of Massachusetts's Medicare population and 19\% of its Medicaid population. ${ }^{17}$ These rates are much higher than the national representation of dual eligible patients in Medicare and Medicaid programs. ${ }^{17}$ Roughly $40 \%$ of this population was composed of enrollees under the age of 65 years, ${ }^{18}$ two thirds of whom had a behavioral health diagnosis. ${ }^{19}$ Our findings underscore the disproportionate service utilization by a highrisk patient population at safety net medical centers.

This study has several strengths. First, a large number of patients met the study selection criteria and were included in the analytical sample. Second, the integrity of analytical data was strong; only 3 sample patients were excluded because of incomplete demographic information. Third, the variety of available demographic data and similar distributions of unmeasured characteristics allowed for estimation of a multidimensional propensity score-matched analysis that balanced the treatment and control groups to approximate randomization. The resulting overlap in propensity scores between the group with behavioral health illness and the group without behavioral health illness was significant and permitted good matching properties.

These results have implications for managed care pharmacy programing and policymaking. Determining the best methods to coordinate care for this patient population could have positive downstream effects on quality and cost of care..$^{20}$ 

Stratified by Presence of Behavioral Health Illness, 2011

\begin{tabular}{|c|c|c|c|c|c|}
\hline & \multicolumn{2}{|c|}{$\begin{array}{c}\text { Patients with } \\
\text { Behavioral Health Illness }{ }^{\mathrm{a}} \\
(\mathrm{n}=3,089)\end{array}$} & \multicolumn{2}{|c|}{$\begin{array}{c}\text { Patients Without } \\
\text { Behavioral Health Illness } \\
(\mathbf{n}=3,089)\end{array}$} & $P$ Value \\
\hline \multicolumn{6}{|l|}{ Demographics $^{b}$} \\
\hline Age on January 1, 2011, mean (SD) & 46.3 & $(11.1)$ & 46.6 & $(11.7)$ & 0.084 \\
\hline Female, n (\%) & 1,482 & $(48.0)$ & 1,410 & $(45.6)$ & $0.027^{c}$ \\
\hline \multicolumn{6}{|l|}{ Race/ethnicity, n (\%) } \\
\hline White & 1,204 & $(39.0)$ & 1,251 & $(40.5)$ & 0.148 \\
\hline Non-Hispanic black & 1,274 & $(41.2)$ & 1,318 & $(42.7)$ & 0.178 \\
\hline Hispanic & 486 & $(15.7)$ & 415 & $(13.4)$ & $0.002^{\mathrm{c}}$ \\
\hline Other/unknown & 125 & $(4.0)$ & 105 & $(3.4)$ & 0.136 \\
\hline \multicolumn{6}{|l|}{ Marital status, n (\%) } \\
\hline Single & 2,206 & $(71.4)$ & 2,199 & $(71.2)$ & 0.825 \\
\hline Married & 332 & $(10.7)$ & 336 & $(10.9)$ & 0.852 \\
\hline Divorced/separated & 427 & $(13.8)$ & 438 & $(14.2)$ & 0.660 \\
\hline Other/Unknown & 124 & $(4.0)$ & 116 & (3.8) & 0.581 \\
\hline \multicolumn{6}{|l|}{ Education, $\mathrm{n}(\%)$} \\
\hline$\leq$ High school & 2,127 & $(68.9)$ & 2,172 & $(70.3)$ & 0.150 \\
\hline Some college & 249 & $(8.1)$ & 231 & $(7.5)$ & 0.370 \\
\hline College graduate & 391 & $(12.7)$ & 417 & $(13.5)$ & 0.270 \\
\hline None & 78 & $(2.5)$ & 61 & $(2.0)$ & 0.135 \\
\hline Other/unknown & 244 & $(7.9)$ & 208 & $(6.7)$ & $0.035^{c}$ \\
\hline \multicolumn{6}{|l|}{ Employment status, n (\%) } \\
\hline Full-time & 68 & $(2.2)$ & 67 & $(2.2)$ & 0.928 \\
\hline Part-time & 71 & $(2.3)$ & 81 & $(2.6)$ & 0.365 \\
\hline Disabled & 1,410 & $(45.6)$ & 1,417 & $(45.9)$ & 0.830 \\
\hline Unemployed & 1,294 & $(41.9)$ & 1,313 & $(42.5)$ & 0.554 \\
\hline Other/unknown & 246 & $(8.0)$ & 211 & $(6.8)$ & $0.049^{c}$ \\
\hline \multicolumn{6}{|l|}{ Physical comorbidities, n (\%) } \\
\hline Chronic pulmonary disease & 540 & $(17.5)$ & 504 & $(16.3)$ & 0.117 \\
\hline Diabetes without chronic complications & 362 & $(11.7)$ & 338 & $(10.9)$ & 0.301 \\
\hline Moderate or severe liver disease & 283 & $(9.2)$ & 260 & $(8.4)$ & 0.236 \\
\hline Diabetes with chronic complications & 196 & $(6.3)$ & 192 & $(6.2)$ & 0.829 \\
\hline Renal disease & 173 & $(5.6)$ & 145 & $(4.7)$ & 0.092 \\
\hline AIDS/HIV & 173 & $(5.6)$ & 162 & $(5.2)$ & 0.506 \\
\hline Congestive heart failure & 132 & $(4.3)$ & 126 & $(4.1)$ & 0.697 \\
\hline Peripheral vascular disease & 110 & $(3.6)$ & 93 & $(3.0)$ & 0.204 \\
\hline Cancer & 99 & $(3.2)$ & 94 & $(3.0)$ & 0.707 \\
\hline Cerebrovascular disease & 89 & $(2.9)$ & 84 & $(2.7)$ & 0.697 \\
\hline Myocardial infarction & 86 & $(2.8)$ & 78 & $(2.5)$ & 0.530 \\
\hline Hemiplegia or paraplegia & 60 & $(1.9)$ & 64 & $(2.1)$ & 0.708 \\
\hline Rheumatic disease & 38 & $(1.2)$ & 52 & $(1.7)$ & 0.136 \\
\hline Metastatic solid tumor & 30 & $(1.0)$ & 30 & $(1.0)$ & 1.000 \\
\hline Peptic ulcer disorder & 15 & $(0.5)$ & 15 & $(0.5)$ & 1.000 \\
\hline Dementia & $\mathrm{NA}^{\mathrm{d}}$ & $\mathrm{NA}^{\mathrm{d}}$ & $\mathrm{NA}^{\mathrm{d}}$ & $\mathrm{NA}^{\mathrm{d}}$ & $\mathrm{NA}^{\mathrm{d}}$ \\
\hline Charlson Comorbidity Index, mean (SD) & 1.3 & $(2.2)$ & 1.2 & $(2.1)$ & 0.067 \\
\hline \multicolumn{6}{|c|}{$\begin{array}{l}\text { 'P values < } 0.05 \text {; calculated using McNemar's tests for categorical variables and Wilcoxon signed-rank tests for co } \\
d N A \text { indicates that fewer than } 10 \text { patients fell within that cell, so the result was deleted. } \\
\text { AIDS/HIV = acquired immunodeficiency syndrome/human immunodeficiency virus; SD=standard deviation. }\end{array}$} \\
\hline
\end{tabular}


TABLE 3 Postmatch Utilization Rates of Adult Dual Eligible Patients, 2011

\begin{tabular}{|c|c|c|c|c|c|c|c|c|}
\hline \multirow[b]{2}{*}{ Utilization } & \multicolumn{2}{|c|}{$\begin{array}{l}\text { Patients with Behavioral } \\
\text { Health Illness }\end{array}$} & \multicolumn{2}{|c|}{$\begin{array}{c}\text { Patients Without Behavioral } \\
\text { Health Illness }\end{array}$} & \multicolumn{2}{|c|}{ Postmatch ${ }^{b}$} & \multicolumn{2}{|c|}{ Postmatch Adjusted ${ }^{c}$} \\
\hline & Count & Rate & Count & Rate & RR $(95 \% \mathrm{CI})^{\mathrm{d}}$ & $P$ Value $^{e}$ & $\mathrm{RR}(95 \% \mathrm{CI})^{\mathrm{d}}$ & $P$ Value $^{\mathrm{e}}$ \\
\hline Hospital admissions & 1,398 & 0.45 & 675 & 0.22 & $\begin{array}{c}2.07 \\
(1.81-2.38)\end{array}$ & $<0.001^{\mathrm{f}}$ & $\begin{array}{c}2.14 \\
(1.87-2.46)\end{array}$ & $<0.001^{\mathrm{f}}$ \\
\hline $\begin{array}{l}\text { Emergency department } \\
\text { visits }\end{array}$ & 3,354 & 1.09 & 2,089 & 0.68 & $\begin{array}{c}1.61 \\
(1.46-1.77) \\
\end{array}$ & $<0.001^{\mathrm{f}}$ & $\begin{array}{c}1.64 \\
(1.49-1.81) \\
\end{array}$ & $<0.001^{\mathrm{f}}$ \\
\hline $\begin{array}{l}\text { aPatients were defined as } \\
\text { corresponding diagnosis fo } \\
\text { bUnadjusted RRs and } 95 \% \\
\text { a patient had a behavioral } \\
\text { cRegression-adjusted RRs } \\
\text { physical comorbidities that } \\
\text { was Hispanic, whether a } p \\
\text { measures were included in } \\
{ }^{d} R R \text { s were calculated to co } \\
(n=3,089) \text {. } \\
\text { eP values were estimated } f_{1} \\
f P<0.05 \text {. }\end{array}$ & $\begin{array}{l}\text { a behavio } \\
\text { ohavioral } \\
\text { ere estime } \\
\text { illness. } \\
\text { timated } \\
\text { still statis } \\
\text { had "othe } \\
\text { gression } m \\
\text { the occur } \\
\text { e unadjus }\end{array}$ & $\begin{array}{l}\text { illness if } \\
\text { ness. } \\
\text { GLM reg } \\
\text { ubject me } \\
1 \text { regressio } \\
\text { nificant af } \\
\text { inown" en } \\
\text { iccount fo } \\
\text { vents bet } \\
\text { djusted re }\end{array}$ & $\begin{array}{l}\text { had a medic } \\
\text { ons with a lo } \\
\text { es were inclu } \\
\text { th a log link } \\
\text { natching bets } \\
\text { ment status, } \\
\text { tching betwe } \\
\text { dual eligible } \\
\text { ion models. } \\
\text { ratio. }\end{array}$ & $\begin{array}{l}\text { the Boston } \\
\text { tion and a } \\
\text { regression } \\
\text { nd a negat } \\
\text { nts with ar } \\
\text { her a patie } \\
\text { vith behavi }\end{array}$ & $\begin{array}{l}\text { ledical Center } \\
\text { egative binomic } \\
\text { odels to accoun } \\
\text { binomial distr } \\
\text { without behavi } \\
\text { had "other" or } \\
\text { al health illnes }\end{array}$ & $\begin{array}{l}\text { anuary } 1 \\
\text { ribution, } \\
\text { natching } \\
\text { n. The c } \\
\text { ealth con } \\
\text { nown" ed } \\
\text {,089) an }\end{array}$ & $\begin{array}{l}\text { single covaric } \\
\text { en patients. } \\
\text { tes included al } \\
\text { lities (gender, } \\
\text { in status). Repe } \\
\text { e without beha }\end{array}$ & $\begin{array}{l}\text { 011, with a } \\
\text { g for whether } \\
\text { ographics an } \\
\text { er a patient } \\
\text { subject } \\
\text { health illnes }\end{array}$ \\
\hline
\end{tabular}

There are multiple efforts to improve medication adherence in the dual eligible patient population. ${ }^{21,22}$ Managed care services are often involved in coordinating posthospitalization activities, as well as managing pharmacy access and benefits for this patient population. Therefore, in this fee-for-service Medicaid population, further study should be done to assess how Medicaid managed care activities affect similar outcomes. At the state and local level, infrastructure costs for these activities can be high, so federal funds should be targeted towards organizations to deliver high quality care to this population. Since a large proportion of the most costly patient population continues to use safety net hospitals such as Boston Medical Center, federal funds should continue to support the care of these patients and should account for direct and indirect disease burdens.

\section{Limitations}

This study has several limitations. The analysis focused on a patient population that used a single medical center (Boston Medical Center) during a single year (2011); therefore, study results cannot be generalizable to the entire U.S. population. While we only studied a single year, to ensure that we were not studying unique trends, we conducted a sensitivity analyses evaluating patient characteristics and medical resource utilization among dual eligible patients during the previous 2 years (2009 and 2010). Our analysis revealed no significant differences in data as they pertained to the population sample or utilization outcomes.

Data evaluated in this study also were limited to information recorded in patient electronic medical records. For instance, if errors were made in data input or collection, such errors would be transferred onto our analysis. Several measures were taken to strengthen the integrity of the data. For instance, length of stay measures were used to identify hospital admission and discharge dates correctly. Dual eligible patients enrolled in managed care organizations were excluded because sensitivity analyses demonstrated that such dual eligible patients were significantly different from those outside managed care organizations. Furthermore, in this time frame, dual eligible patients were less likely to enroll in managed care than Medicaid-only disabled adults ( $35.1 \%$ vs. $11.7 \%)^{23}$

Finally, the use of propensity score matching only accounted for observable demographic and clinical characteristics. Unobservable patient characteristics that might have affected whether or not a patient had behavioral health illness, such as living conditions, were therefore not available in the matching procedure. Despite the absence of such unobservable characteristics, covariates included in the propensity score match generated a close fit between patient cohorts with few statistically significant or clinically meaningful differences after matching.

\section{Conclusions}

This study found that adult fee-for-service Medicare and Medicaid patients aged under 65 years with behavioral health illness have significantly increased rates of hospital admission and ED use compared with their counterparts without behavioral health illness. These findings also demonstrate the burden of disease and use that continue to affect the largest safety net hospital in New England. Further research is needed to elucidate the systems-related and patient-centered factors contributing to the utilization behaviors of this patient population. 


\section{Authors}

RAMON S. CANCINO, MD, MSc, Department of Family \& Community Medicine, University of Texas Health Science Center at San Antonio, Joe R. E Teresa Lozano Long School of Medicine. BRIAN W. JACK, MD, Department of Family Medicine, Boston University School of Medicine/Boston Medical Center, Boston, Massachusetts. JOHN JARVIS, BA; ALICE KATE CUMMINGS, BA; ELLIE COOPER, BA; and PIERRE-YVES CREMIEUX, PhD, Analysis Group, Boston, Massachusetts. JAMES F. BURGESS, JR., $\mathrm{PhD}$, Center for Healthcare Organization and Implementation Research, VA Boston Healthcare System, and Department of Health Policy and Management, Boston University School of Public Health, Boston, Massachusetts.

AUTHOR CORRESPONDENCE: Ramon S. Cancino MD, MSc, Assistant Professor, Department of Family \& Community Medicine, University of Texas Health Science Center at San Antonio, Joe R. E Teresa Lozano Long School of Medicine, 7703 Floyd Curl Dr., San Antonio, TX 78229. Tel.: 210.450.6820;

E-mail: cancinor@uthscsa.edu.

\section{DISCLOSURES}

This research was funded in part by a National Research Service Award (T3HP10028-14-01). The authors have no conflicts of interests to disclose.

Cancino had full access to all of the data in the study and takes responsibility for the integrity of the data and the accuracy of the data analysis. Study concept and design were contributed by Cancino, Jack, and Burgess, with assistance from Cremieux. Cancino and Cremieux took the lead in data collection, along with Jack and Burgess, and data interpretation was performed by Jarvis, Cummings, and Cooper, along with the other authors. The manuscript was written primarily by Cancino, along with Jack and Burgess, and revised primarily by Cancino, along with the other authors.

\section{REFERENCES}

1. Meyer $\mathrm{H}$. The coming experiments in integrating and coordinating care for "dual eligibles." Health Aff (Millwood). 2012;31(6):1151-55.

2. Feder J, Clemans-Cope L, Coughlin T, Holahan J, Waidmann T. Refocusing responsibility for dual eligibles: why Medicare should take the lead. Robert Wood Johnson Foundation and the Urban Institute. October 2011. Available at: http://www.urban.org/sites/default/files/ publication/27621/412418-Refocusing-Responsibility-For-Dual-EligiblesWhy-Medicare-Should-Take-The-Lead.PDF. Accessed May 26, 2017.

3. Jiang HJ, Wier LM, Potter DEB, Burgess J. Potentially preventable hospitalizations among medicare-medicaid dual eligibles, 2008. HCUP Statistical Brief \#96. September 2010. Agency for Healthcare Research and Quality, Rockville, MD. Available at: http://www.hcup-us.ahrq.gov/reports/statbriefs/ sb96.pdf. Accessed May 26, 2017.

4. Moon S, Shin J. Health care utilization among Medicare-Medicaid dual eligibles: a count data analysis. BMC Public Health. 2006;6:88. Available at: https:// www.ncbi.nlm.nih.gov/pmc/articles/PMC1450274/. Accessed May 26, 2017.

5. Jacobson G, Neuman T, Damico A. Medicare's role for dual eligible beneficiaries. Kaiser Family Foundation Medicare Policy. Issue Brief. April 2012. Available at: https://kaiserfamilyfoundation.files.wordpress. com/2013/01/8138-02.pdf. Accessed May 26, 2017.
6. Gimm G, Blodgett E, Zanwar P. Examining access to care for younger vs. older dual-eligible adults living in the community. Disabil Health J. 2016;9(3):431-38

7. Morden NE, Garrison LP. Implications of Part D for mentally ill dual eligibles: a challenge for Medicare. Health Aff (Millwood). 2006;25(2):491-500. 8. Walsh EG, Clark WD. Managed care and dually eligible beneficiaries: challenges in coordination. Health Care Financ Rev. 2002;24(1):63-82.

9. American Psychiatric Association. Diagnostic and Statistical Manual of Mental Disorders (DSM-IV). 4th ed. Washington, DC; American Psychiatric Association; 2000.

10. World Health Organization. International Classification of Diseases, Ninth Revision. Geneva: World Health Organization; 1980.

11. Andersen RM. Revisiting the behavioral model and access to medical care: does it matter? J Health Soc Behav. 1995;36(1):1-10.

12. Quan H, Sundararajan V, Halfon P, et al. Coding algorithms for defining comorbidities in ICD-9-CM and ICD-10 administrative data. Med Care. 2005;43(11):1130-39.

13. Charlson ME, Pompei P, Ales KL, MacKenzie CR. A new method of classifying prognostic comorbidity in longitudinal studies: development and validation. J Chronic Dis. 1987;40(5):373-83.

14. Bennett KJ, Probst JC. Thirty-day readmission rates among dual-eligible beneficiaries. J Rural Health. 2016;32(2):188-95.

15. West JC, Wilk JE, Muszynski IL, et al. Medication access and continuity: the experiences of dual-eligible psychiatric patients during the first 4 months of the Medicare prescription drug benefit. Am J Psychiatry. 2007;164(5):789-96.

16. Donohue JM, Huskamp HA, Zuvekas SH. Dual eligibles with mental disorders and Medicare Part D: how are they faring? Health Aff (Millwood) 2009;28(3):746-59.

17. Centers for Medicare \& Medicaid Services. Medicare-Medicaid enrollee state profiles. June 13, 2012. Revised January 18, 2017. Available at: https:// www.cms.gov/Medicare-Medicaid-Coordination/Medicare-and-MedicaidCoordination/Medicare-Medicaid-Coordination-Office/StateProfiles.html. Accessed May 26, 2017

18. Crowe J. How competition benefits dual-eligible beneficiaries of Medicare and Medicaid. The Heritage Foundation. July 10, 2014. Available at: http://www.heritage.org/health-care-reform/report/how-competitiveprivate-plans-can-improve-care-dual-eligible. Accessed May 26, 2017.

19. Davidson EB, Dreyfus T. Dual eligibles in Massachusetts: a profile of health care services and spending for non-elderly adults enrolled in both Medicare and Medicaid. Blue Cross Blue Shield of Massachusetts Foundation. September 11, 2011. Available at: http://bluecrossmafoundation. org/event/event-dual-eligibles-massachusetts-profile-health-care-servicesand-spending-non-elderly. Accessed May 26, 2017.

20. Mechanic D. Seizing opportunities under the Affordable Care Act for transforming the mental and behavioral health system. Health Aff (Millwood). 2012;31(2):376-82.

21. Stroupe KT, Smith BM, Bailey L, et al. Medication acquisition by veterans dually eligible for Veterans Affairs and Medicare Part D pharmacy benefits. Am J Health Syst Pharm. 2017;74(3):140-50.

22. Doyle D, Emmett M, Crist A, Robinson C, Grome M. Improving the care of dual eligible patients in rural federally qualified health centers: the impact of care coordinators and clinical pharmacists. J Prim Care Community Health. 2016;7(2):118-21.

23. Libersky J, Hedley Dodd A, Verghese S. National and state trends in enrollment and spending for dual eligibles under age 65 in Medicaid managed care. Disabil Health J. 2013;6(2):87-94. 
Health Services Utilization Among Fee-for-Service Medicare and Medicaid Patients

Under Age 65 with Behavioral Health IIIness at an Urban Safety Net Hospital

\section{APPENDIX ICD-9-CM Codes for Behavioral Health IIInesses}

Behavioral Health Illness

Psychosis

Substance use disorder

Schizophrenic disorders

Dementia

Alcoholic-induced mental disorders

Drug induced mental disorders

Transient mental disorders due to conditions classified elsewhere

Persistent mental disorders due to conditions classified elsewhere

Delusional disorders

Other nonorganic psychoses

Pervasive development disorders

Anxiety, dissociative, and somatoform disorders

Personality disorders

Sexual and gender identity disorders

Other alcoholic intoxication (acute, or chronic in remission)

Drug dependence, in remission

Nondependent abuse of drugs

Physiological malfunction arising from mental factors

Special symptoms or syndromes, not elsewhere classified

Acute reaction to stress

Adjustment reaction

Specific nonpsychotic mental disorders due to organic brain damage

Depressive disorder, not elsewhere classified

Disturbance of conduct, not elsewhere classified

Disturbance of emotions specific to childhood or adolescence

Hyperkinetic syndrome of childhood

Specific delays in development

Psychic factors associated with diseases classified elsewhere

Mild intellectual disabilities

Other specified intellectual disabilities

Unspecified intellectual disabilities
ICD-9-CM Codes

296.xx, 296.0x, 296.1x, 296.2x, 296.3x, 296.4x, 296.5x, 296.6x, 298.9x

303.9x, 304.00, 304.01, 304.02, 304.10, 304.11, 304.12, 304.20, 304.21, 304.22,

$304.30,304.31,304.32,304.40,304.41,304.42,304.50,304.51,304.52,304.60$

$304.61,304.62$, 304.70, 304.71, 304.72, 304.80, 304.81, 304.82, 304.90, 304.91, 304.92

295.xx

290.xx, 294.1x, 331.2x

291.xx

292.xx

293.xx

294.xx

297.xx

298.0x, 298.1x, 298.2x, 298.3x, 298.4x, 298.8x

299.xx

300.xx

$301 . x x$

302.xx

$303.0 x, 303.93$

$304.03,304.13,304.23,304.33,304.43,304.53,304.63,304.73,304.83,304.93$

$305 . x x$

306.xx

307.xx

308.xx

309.xx

310.xx

311.xx

312.xx

313.xx

314.xx

315.xx

316.xx

317.xx

318.xx

319.xx

ICD-9-CM = International Classification of Diseases, Ninth Revision, Clinical Modification. 